\title{
1 The Increasing Incidence of Celiac Disease and the Range of Gluten-Free Products in the Marketplace
}

\author{
Pamela Cureton and Alessio Fasano
}

\subsection{INTRODUCTION}

Celiac disease (CD) is an immune-mediated enteropathy triggered by the ingestion of gluten in genetically susceptible individuals. Gluten is the protein component in wheat, rye and barley. Recent advances have increased our understanding of the molecular basis for this disorder. In the last 10 years, cutting edge scientific developments in this disease have led to the formulation of new concepts of epidemiology, pathophysiology and clinical manifestations. At present, the only available treatment for $\mathrm{CD}$ is a strict gluten-free diet (GFD).

The GFD is not an easy undertaking as gluten-containing grains, especially wheat, are the main ingredients in culturally popular foods such as bread, pasta and cakes. These grains are also widely used as additives, binders, preservatives and thickeners in a vast majority of processed foods such as broths, marinades, processed meats, canned goods, candy and medications. In 2004, the average American consumed 133 pounds $(60.4 \mathrm{~kg})$ of wheat and Canadians consumed 150 pounds ( $68 \mathrm{~kg}$ ). In the United Kingdom, wheat consumption averages 167 pounds (76 kg) per year (Agriculture and Agri-Food Canada, 2004).

Fortunately, both medical knowledge and quality of the GFD continue to improve as awareness of $\mathrm{CD}$ increases throughout the world. At this time, people suffering from the effects of $\mathrm{CD}$ are being diagnosed more quickly than any other time in history. Manufacturers have also responded to the increased need for and potential profit in providing gluten-free foods.

\subsection{HISTORY OF CD EPIDEMIOLOGY: INCREASE INCIDENCE OR INCREASING AWARENESS?}

\subsubsection{Epidemiology of CD in Europe}

In the past four decades, a substantial number of epidemiological studies have been conducted in Europe to establish the frequency of CD, and interesting controversies have arisen. Earlier investigations measured the incidence of $\mathrm{CD}$, namely the number of 'new' diagnoses in the study population during a certain period of time. One of the oldest epidemiological studies on CD conducted in 1950 established that the cumulative incidence of the disease in England and Wales was 1/8000, while an incidence of 1/4000 was detected in Scotland (Davidson and Fountain, 1950). The diagnosis at that time was entirely based on the detection of typical symptoms and confirmed by complicated and sometimes non-specific tests. The awareness 
of the disease greatly increased in the 1960s when more specific tests for malabsorption and the pediatric peroral biopsy technique became available (Meeuwisse, 1970). Consequently, an elevated incidence of the disease (that in the mid-1970s reached peaks of 1/450-500) was reported in studies from Ireland (Mylotte et al., 1973), Scotland (Logan et al., 1986) and Switzerland (Van Stirum et al., 1982). This increased incidence of CD urged changes in the dietary habit, based on the hypothesis that delayed exposure to gluten could prevent the onset of the disease. For the first time in 25 years, a decrease in the incidence of CD was reported in the United Kingdom and Ireland (Littlewood et al., 1980; Dossetor et al., 1981; Stevens et al., 1987) following a late introduction of gluten in infant diet. Unfortunately, this decrease was deceptive, since subsequent screening studies demonstrated that the reduction of typical cases in infants was counterbalanced by the increase of atypical forms of CD with the onset of the symptoms occurring in older children or in adults (Greco et al., 1922). Due to the development of sensitive serological tests, it has recently become possible to evaluate the prevalence of $\mathrm{CD}$ (number of affected persons - including subclinical cases - in a defined population at a certain point in time). Screening studies have demonstrated a high prevalence of CD both among healthy children (Catassi et al., 1984, 1995; Mazzetti di Pietralata et al., 1992) and adults (Grodzinsky et al., 1992). The prevalence of CD throughout the old continent seems to be more homogeneous than previously thought (Table 1.1). Furthermore, these screenings revealed that $\mathrm{CD}$ is one of the most frequent genetically based diseases (Catassi et al., 1984; Ascher et al., 1991) occurring in 1 out of 130-300 in the European population (Catassi et al., 1996; Kolho et al., 1998) (Table 1.1). In a serological screening study involving more than 17000 Italian schoolchildren, the prevalence of CD was 1 in 184 (Maki et al., 1988) and the ratio of known to undiagnosed $\mathrm{CD}$ cases resulted to be 1:7. The European experience taught that, despite common genetic and environmental factors, the clinical presentation of $\mathrm{CD}$ in neighboring countries may greatly diverge. A typical example of this phenomenon is the Danish epidemiological case. Until a few years ago, CD was regarded as rare in Denmark, with an estimated incidence based on clinical evidence (i.e. the presence of classical symptoms) of 1/10000 (Weile and Krasilnifoff, 1993) (Table 1.1). At the same

Table 1.1 Comparison between prevalence on clinical diagnosis and on screening data in several countries worldwide.

\begin{tabular}{lll}
\hline Geographic area & $\begin{array}{l}\text { Prevalence on clinical } \\
\text { diagnosis }^{\text {a }}\end{array}$ & $\begin{array}{l}\text { Prevalence on } \\
\text { screening data }\end{array}$ \\
\hline Brazil & 2 & $1: 400$ \\
Denmark & $1: 10000$ & $1: 500$ \\
Finland & $1: 1000$ & $1: 130$ \\
Germany & $1: 2300$ & $1: 500$ \\
Italy & $1: 1000$ & $1: 184$ \\
Netherlands & $1: 4500$ & $1: 198$ \\
Norway & $1: 675$ & $1: 250$ \\
Sahara & $?$ & $1: 70$ \\
Slovenia & $?$ & $1: 550$ \\
Sweden & $1: 330$ & $1: 190$ \\
United Kingdom & $1: 300$ & $1: 112$ \\
United States & $1: 10000$ & $1: 133$ \\
Worldwide (average) & $1: 3345$ & $1: 266$ \\
\hline
\end{tabular}

Source: Reprinted from Fasano and Catassi (2001), p. 16, copyright 2001, with permission from Elsevier.

${ }^{a}$ Classical gastrointestinal symptoms. 
time, the incidence of the disease in neighboring countries (including Sweden and Finland) that share similar genetic backgrounds increased following a decrease in breast-feeding practice and an increased consumption of gluten during infancy (Ascher et al., 1991; Maki et al., 1992). Subsequent serological screening studies suggested that CD is as frequent in Denmark as in Sweden, with a reported prevalence of 1/500 (Ascher and Kristiansson, 1994) (Table 1.1). These results suggest that in Denmark most cases of CD were previously undiagnosed, presumably because of lack of typical gastrointestinal symptoms. Factors such as type of cow's milk formulae, breast feeding, age at gluten introduction, quantity of gluten and quality of cereals, and quantity of wheat gluten may all influence the clinical presentation of the disease (Maki et al., 1992).

\subsubsection{Epidemiology of CD in the United States}

Within the American scientific community it was generally held that $\mathrm{CD}$ was a rare disorder in the United States, which was reflected by the limited number of scientific papers published from the new continent in the 30 years period 1965-1995 (Fasano, 1996). Remarkably, only two epidemiological studies on CD were published during this period, both between 1993 and 1994. The first study was conducted by Rossi et al. (1993) on a pediatric population from the western New York area with symptoms possibly related to CD, as chronic diarrhea, failure to thrive, short stature and diabetes. While the prevalence of CD among patients with symptoms possibly associated to the disease was lower than reported in Europe, the concurrence of $\mathrm{CD}$ and type 1 diabetes were comparable to that previously reported from the Old Continent. These data suggested that other atypical presentations of CD and eventually the late onset of the disease after an asymptomatic phase during childhood may account for the low occurrence of CD reported in this study. The second American epidemiological study published in 1994 was based on a retrospective evaluation (1960-1990) of the incidence of CD among the population of Olmsted County, Minnesota using the medical record of the Rochester Epidemiological Project (Talley et al., 1994). Case definition was limited to those individuals presenting typical gastrointestinal symptoms (i.e. chronic diarrhea and weight loss) or dermatitis herpetiformis whose intestinal biopsy showed a flat mucosa (Talley et al., 1994). Using these restrictive parameters, the authors identified only three cases among the pediatric population (calculated incidence rate: 0.4 per 100000 person-year), while the overall age- and gender-adjusted incidence was 1.2 per 100000 person-year. Based on these results, the authors concluded that CD is relatively rare in the United States (prevalence $\sim 1: 10000$ ). Unfortunately, both studies failed to consider the protean clinical manifestations of CD. By focusing on specific symptoms, the authors may have missed what is currently defined as the submerged part of the so-called celiac iceberg. Recently, a series of epidemiological studies conducted by using more appropriate experimental designs and powerful screening tools have demonstrated that CD in the United States is as frequent as in Europe in both risks groups (Hill et al., 1995, 2000; Catassi et al., 2007) and the general population (Not et al., 1998; Berti et al., 2000; Fasano et al., 2003) (Table 1.1). Our center for celiac research has conducted a large, multicenter study on the prevalence of CD in both risk groups (i.e. subjects with either symptoms or complications associated to $\mathrm{CD}$, first and second degree relatives of biopsy-proved CD patients, etc.) and the general population. Our results showed for the first time that the prevalence of CD in the United States is similar to that reported in Europe if not even higher, both among risk groups and the general population (Fasano et al., 2003) (Table 1.1). 


\subsubsection{Epidemiology of $C D$ in the rest of the world}

Since CD is the result of the interaction between genetic (both HLA (human leukocyte antigen) and non-HLA associated genes) and environmental factors (gluten-containing grains), it would be reasonable to evaluate the world distribution of these two components in order to identify area 'at risk' for CD. The coincidence of the CD HLA aplotypes and the level of wheat consumption clearly confirm Europe as a region at risk for CD (Fasano and Catassi, 2001). However, the co-existence of the two key components involved in CD pathogenesis is also notable in regions where $\mathrm{CD}$ has been historically considered rare. A more attentive analysis of these pathogenic factors can possibly explain this apparent paradox.

\subsubsection{CD causal factors show a worldwide distribution}

The principal genetic and environmental factors responsible for the development of CD show a worldwide distribution (Fasano and Catassi, 2001). The consumption of gluten-containing cereals is widespread in Europe, North Africa, North and South America and part of the Asian continent. In India, wheat consumption is higher in the so-called 'celiac belt', that is, the North-Western group of states where this cereal is the staple diet (Punjab, Haryana, Delhi, Rajasthan and Uttar Pradesh) (Yachha, 2006). This finding explains why in India CD has mostly been described in the Northern part of the country, a situation that might change in the future due to Westernization of the diet. In India, as well in other Asian countries, there is a clear slowing of per capita consumption of rice and an increased consumption of wheat-based products. Rising income and urbanization are driving forces in the rise of wheat consumption. Whereas wheat is considered an inferior good in Western societies, in the traditional rice-eating countries in Asia, wheat is becoming a preferred staple. Because of these alimentary trends, an increasing incidence of CD in India should be expected in the near future.

The major HLA-related predisposing genotypes (DQ2 and DQ8) have consistently been found in most populations of the world, with a few exceptions (e.g. Highlanders in Papua New Guinea). However, the geographical distribution of the different HLA-DQ predisposing genotypes is still incomplete. A variable frequency of either high- (e.g. DQ2 in homozygosity) or low/moderate risk (e.g. DQ8) genotypes could contribute to explaining the variable prevalence of $\mathrm{CD}$ that has been reported in different parts of the world.

\subsubsection{2 $C D$ is increasingly reported from the developing world}

Until recently, the geographical distribution of CD was mostly restricted to Europe and other developed countries, such as the United States, Canada and Australia. New epidemiological studies have brought evidence that this disorder is common in many developing countries as well, showing that the 'global village of celiac disease' has indeed a worldwide distribution (Catassi et al., 2005).

The presence of CD is long established in many South American countries that are mostly populated by individuals of European origin. Among Brazilian blood donors, the prevalence of CD ranged between 1:681 (Gandolfi et al., 2000) and 1:214 (Oliveira et al., 2007). It is worth noting that studies on blood donors tend to underestimate the prevalence of $\mathrm{CD}$, as these individuals represent the 'healthiest' segment of the population and are mostly males (while CD is more common among women). In Argentina, Gomez et al. (2001) found an 
overall prevalence of 1 on 167 on 2000 adults involved in a prenuptial examination (Gomez et al., 2001).

Although the frequency of $\mathrm{CD}$ in many parts of Africa is still unknown, it is nowadays clear that this condition is present in the African continent. The highest CD prevalence in the world has indeed been described in an African population originally living in Western Sahara, the Saharawi, of Arab-Berber origin. In a sample of 990 Saharawi children screened by EMA (anti-endomysial antibody) testing and intestinal biopsy, the prevalence of CD was found to be 5.6\%, which is almost tenfold higher than in most European countries (Catassi et al., 1999). The reasons for this spiking CD frequency are unclear but could be primarily related to genetic factors, given the high level of consanguinity of this population. The main susceptibility genotypes, HLA-DQ2 and -DQ8, exhibit one of the highest frequencies in the world in the general background Saharawi population (Catassi et al., 2001). Gluten consumption is very high as well, since wheat flour is the staple food of the Saharawi refugees. A recently completed screening project on school children in Cairo City, Egypt, on both a general population sample and at-risk subjects showed that $\mathrm{CD}$ is a common and usually undiagnosed disorder among Egyptian children (Abu-Zekry et al., 2008). The prevalence in the general population was $0.53 \%$, that is $1: 187$, a figure that overlaps with European, North American and North African data. The Egyptian study confirmed that most screening-detected CD cases in North Africa are subclinical, with a mild degree of growth failure and anemia as frequent findings. A significantly higher prevalence of $\mathrm{CD}$ was found in the same study in children hospitalized for diarrhea and/or malnutrition (2.36\%) and children affected with type 1 diabetes (6.4\%), confirming that subjects presenting with these at-risk conditions should always be serologically screened for CD. In a recent mass screening for CD performed in Ariana, Tunisia, on 6284 children tested by tTGA and EMA plus small bowel biopsy in suspected cases, a prevalence of 1:157 was found (Ben Hariz et al., 2007). Most of the screened Tunisian children were asymptomatic or had atypical CD. Indirect evidence suggests that $\mathrm{CD}$ is not a rare disorder in other Northern African countries. Large series of clinically diagnosed patients have been reported from Algeria (Mediene et al., 1995) and Libya (al-Tawaty and Elbargarthy, 1998). Furthermore, CD is one of the most common disorders diagnosed in children born from North African immigrants in European countries.

$\mathrm{CD}$ is a frequent disorder in Middle East and along the 'silk road' countries. One of the higher prevalence of CD in blood donors has indeed been reported from Iran (1 in 167). In the same country, $12 \%$ of cases with a diagnosis of irritable bowel syndrome for many years were actually affected by CD (Shahbazkhani et al., 2003). In studies from Iran, Iraq, Saudi Arabia and Kuwait, CD accounted for $20 \%$ and $18.5 \%$ of cases with chronic diarrhea in adults and children, respectively. In a study from Jordan, the high incidence of CD was related to the large wheat consumption of the population (135 kg/head/year) (Rawashdeh et al., 1996).

With the availability of improved and more accessible diagnostic tools, $\mathrm{CD}$ is being more and more frequently recognized in India, both in children and in adults. By using a casefinding approach (serological testing on symptomatic subjects), Sood et al. (2006) reported a prevalence of newly diagnosed CD of 1 in 310 children on a sample of 4347 school-age children from Punjab, India. CD in Indian children is predominantly associated with the DQ2 allele, often in linkage disequilibrium with the A26-B8-DR3 alleles (the so-called Indian haplotype, a variant of the ancestral Caucasian haplotype A1-B8-DR3-DQ2) (Kaur et al., 2002). 
Finally, there are only anecdotal reports of CD in Far East Countries. Given the low prevalence of HLA predisposing genes DQ2/DQ8 and the low/absent gluten consumption, reduced disease prevalence should be expected in those populations.

\subsubsection{CD frequency is largely underestimated in the developing world}

The burden of CD in developing countries is largely underestimated. This situation depends on several reasons, particularly the common belief that $\mathrm{CD}$ does not exist in developing countries, poor awareness of the clinical variability of $\mathrm{CD}$, scarcity of diagnostic facilities and more emphasis on other causes of small intestinal damage, such as intestinal tuberculosis and environmental enteropathy. It is also possible that the prevalence of $\mathrm{CD}$ is increasing in some developing countries because of the widespread diffusion of Western dietary habits, with increasing consumption of gluten-containing cereals. The abrupt modification of dietary habits may be one of the causes of the huge prevalence of CD among the Saharawis (Catassi et al. 1999, 2001). Historically, the Bedouin diet was based on prolonged breast feeding, camel milk and meat, dates, sugar and small amounts of cereals and legumes. Over the last century, however, the Saharawi dietary habits have changed dramatically because of the European colonization, and products made with wheat flour, especially bread, have become the staple food.

\subsection{EVOLUTION OF THE GLUTEN-FREE DIET}

The treatment for $\mathrm{CD}$ has long been suspected to be linked to the diet. The GFD has evolved over the past 100 years to its current form; however, the first attempts to control the disease by diet were based on less than palatable products. With advances in medicine technology leading to a better understanding of the cause of the disease also came improvements in the GFD.

In 1888, Samuel Jones Gee, an English physician and pediatrician, published the first complete modern description of the clinical picture of CD in a lecture at the Hospital for Sick Children, Great Ormond Street in 1888. Gee theorized on the importance of diet in the treatment for $\mathrm{CD}$ as follows:

\footnotetext{
There is a kind of chronic indigestion which is met with in persons of all ages, yet is especially apt to affect children between one and five years old. Signs of the disease are yielded by the faeces; being loose, not formed, but not watery; more bulky than the food taken would seem to account for; pale in colour, as if devoid of bile; yeasty, frothy, an appearance probably due to fermentation; stinking, stench often very great, the food having undergone putrefaction rather than concoction.
}

Gee identified food as the main part of treatment for $\mathrm{CD}$, and states, '[I]f the patient can be cured at all, it must be by means of diet.' Gee prescribed a diet free of milk, highly starched foods, rice, sago, fruits and vegetables. Raw meat and thin slices of toasted bread were recommended, with the caveat that children 'cannot bear this diet for more than one season' (Gee, 1988).

Improving upon Gee's dietary recommendations, Haas (1924), an American pediatrician, reported a banana diet resulted in positive effects for children with $\mathrm{CD}$. Parents were instructed to feed their children a diet of chicken, rice and bananas, over the course of several years. When their symptoms resolved, these children were started back on a diet containing gluten, 
as at that time, physicians believed that the condition was curable. However, symptoms of CD redevelop, sometimes as late as age 50 or 60 , with notable complications. A patient recently seen at the University of Maryland School of Medicine writes of her celiac experience:

Then on September 21, 1937, my mother dropped me off at the hospital a second time and was told to not come to see me for 6 weeks. I am sure they questioned my survival, although my mother did not. I ended up staying here in this hospital until June 28, 1938 - 9 months and 1 week. Doctor Loring Joslin was my pediatrician and diagnosed my problem as Celiac Disease. My diet became what we knew as baked bananas and Bulgarian butter milk. There was another little boy in the hospital with me with the same problems. We were documented in a 1938 university medical journal as being first survivors. We were known as the Banana Babies.

I lived on the baked bananas and Bulgarian buttermilk for 2-3 years, and in all that time, my mother never tasted it, as it looked so terrible. Bananas were not easy to buy back then either. A family member or a friend, had to go to Baltimore each week to purchase the weekly supply 21 bananas for 3 a day.

My mother was told I would out grow the condition, so other foods were gradually added to my diet and seemed to be tolerated. Dairy products were the last to be added, so by age 6, I could finally eat ice cream.

This diet remained in vogue until the actual cause of CD was determined in the 1950s. While carbohydrates had been suspected from early investigations, the link with wheat was made by the Dutch pediatrician Dr. Willem Dicke in 1950. He noted clinical improvement of his patients during the Dutch famine of 1944 (van Berge-Henegouwen and Mulder, 1993). During this time, wheat, rye, oats and barley were seized for use by the German armies and the Dutch population was living on bread made with flour ground from tulip bulbs. After the war ended and wheat consumption resumed, children's symptoms of CD recurred.

Until the groundbreaking multicenter study on the prevalence of CD in the United States was published in 2003, CD was considered rare in that country, and few patients were correctly diagnosed. With no demand for special foods, no gluten-free products were manufactured until 1978, when small companies began manufacturing wheat-free, gluten-free breads. After this study's finding that 1 in 133 people (1\% of the US population) suffered from CD, government agencies became involved on both the medical and manufacturing aspects of the treatment of CD (Fasano et al., 2003).

\subsection{US GOVERNMENT AGENCIES BECOME INVOLVED IN CD}

\subsubsection{NIH consensus conference held on CD}

The National Institutes of Health (NIH) convened a Consensus Development and State-ofthe-Science Conference on CD in June 2004. Consensus conferences are convened to review the scientific evidence on a biomedical or public health topic, for the purpose of resolving a particular controversial issue in clinical or public health practices. The objective of the conference was to provide health care providers, patients and the general public with a responsible assessment of currently available data regarding CD (NIH Consensus Statement on Celiac Disease, 2004). The panel concluded that CD was not rare in the United States and actually affected up to 3 million Americans, with the vast majority being undiagnosed. The 
panel recommended the following:

- Education of physicians, dietitians, nurses and the public about CD by a trans-NIH initiative, to be led by the National Institute of Diabetes and Digestive and Kidney Diseases, in association with the Centers for Disease Control and Prevention.

- Standardization of serologic tests and pathologic criteria for the diagnosis of CD.

- Adoption of a standard definition of a GFD based on objective evidence such as that being developed by the American Dietetic Association.

- Development of an adequate testing procedure for gluten in foods and definition of standards for gluten-free foods in the United States to lay the foundation for rational food labeling.

- Formation of a federation of CD societies, CD interest groups, individuals with CD and their families, physicians, dietitians and other health care providers for the advancement of education, research and advocacy for individuals with CD (NIH Consensus Statement on Celiac Disease, 2004).

\subsubsection{Food and Drug Administration institutes a new food labeling law}

Historically, finding safe, gluten-free foods in the market place has been an enormous challenge for people with $\mathrm{CD}$. Grocery shopping became extremely time-consuming, confusing and unproductive. The food labels provided little help in determining whether products were gluten free. Shopping for gluten-free foods takes an average family between 10 and $20 \mathrm{~h}$ per month longer than average consumers, which includes contacting food manufacturers, reading product labels and searching the Internet to identify foods that are free from gluten ingredients and cross-contamination (Gluten Intolerance Group, 2005).

In 2003, the celiac community, including support group leaders, researchers, health care providers and industry representatives, organized a task force with the specific goal of working toward the passage of a new food labeling law. The American Celiac Task Force (now named The American Celiac Disease Alliance) works in conjunction with the Food Allergy and Anaphylaxis Network to change the requirements of food labeling. In 2004, the Food Allergen Labeling and Consumer Protection Act (FALCPA) of 2004 was signed into law. The FALCPA requires that the labels of all FDA-regulated food products, labeled on or after 1 January 2006, clearly state whether a food contains any 'major food allergen'. This law mandates that food manufacturers label, in plain English, the use of any of the top eight allergens in their products, including milk, eggs, fish, shellfish, tree nuts, peanuts, soybeans and wheat (Gomez et al., 2001). The FALCPA greatly simplifies label reading and reduces the possibility of hidden wheat gluten in most packaged foods. FALCPA does not, however, include barley and rye, making it possible for these sources of gluten to be hidden in flavorings and other additives.

\subsubsection{Part two of the FALCPA}

Currently, there is no US Federal regulation that defines the term 'gluten free' in labeling of foods. Based on comments and other information the FDA received during its public meeting on gluten-free food labeling held in August 2005, there is no universal understanding among United States food manufacturers or consumers about the meaning of foods labeled as 'gluten free'. The FDA believes that establishing a definition for the term 'gluten free' and uniform conditions for its use in the labeling of foods will ensure that persons with $\mathrm{CD}$ are not misled and are provided with truthful and accurate information. 
Fortunately, FALCPA addresses this concern as well, directing that no later than 4 years after the date of enactment of FALCPA, the Secretary of Health and Human Services shall issue a final rule to define and permit use of the term 'gluten free' on the labeling of foods. The FDA is proposing to define 'gluten free' to mean that a food bearing this claim does not contain any of the following:

- An ingredient that is a 'prohibited grain', which refers to any species of wheat (e.g. durum wheat, spelt wheat or kamut), rye, barley or their crossbred hybrids.

- An ingredient (e.g. wheat flour) that is derived from a 'prohibited grain' and that has not been processed to remove gluten.

- An ingredient (e.g. wheat starch) that is derived from a 'prohibited grain' that has been processed to remove gluten, if the use of that ingredient results in the presence of $20 \mu \mathrm{g}$ or more gluten per gram of food.

- Or $20 \mu \mathrm{g}$ or more gluten per gram of food.

A food that bears the claim 'gluten free' or a similar claim (e.g. 'free of gluten', 'without gluten' and 'no gluten') in its labeling and fails to meet the conditions specified in the proposed definition of 'gluten free' would be deemed misbranded (Department of Health and Human Services Food and Drug Administration, 2007).

Internationally, there is no agreement on the definition for the term 'gluten free' or universal symbol to designate a product that is gluten free. In several countries (e.g. Canada), foods are labeled gluten free only if they are made without any gluten-containing grains and do not contain any detectable levels of gluten. The Canadian Food Inspection Agency, however, uses a testing method that has an analytical limitation of 20 parts per million (ppm) gluten, leading to a 'gluten-free' label in this country as indicating tested to less than $20 \mathrm{ppm}$ (Case, 2006).

The International Codex standard, used in much of Europe, is in the process of revising the standards for gluten-free foods, but has been unsuccessful thus far, as there was no consensus on acceptable gluten-free levels and the method of testing for gluten. The original 1983 Codex standard defines 'gluten-free' foods as follows:

(a) consisting of or made only from ingredients which do not contain any prolamins from wheat, rye, barley or their crossbred varieties with a gluten level not exceeding $20 \mathrm{ppm}$; or

(b) consisting of ingredients from wheat, rye, barley, oats, spelt or their crossbred varieties which have been rendered 'gluten free', with a gluten level not exceeding $200 \mathrm{ppm}$; or

(c) any mixture of the two ingredients in (a) and (b) with a gluten level not exceeding 200 ppm (Codex Alimentarius Commission, 2008).

When clear standards are in place from the government, food manufacturers can then provide information and safe manufacturing practice needed to give confidence to the celiac consumer needs to find safe gluten-free foods in the marketplace.

\subsection{GROWTH IN THE GLUTEN-FREE MARKETPLACE}

Increased awareness along with proposed regulations across the world for gluten-free labeling has impacted the market, resulting in rapid growth and availability of gluten-free products. A new report from market-research publisher Packaged Facts, New York, estimated that sales of gluten-free products in the United States would top \$696 million in 2006. With projected 
growth of $25 \%$ annually over the next 4 years, the gluten-free market is predicted to expand to $\$ 1.7$ billion by the end of 2010, growing from a modest $\$ 210$ million in 2001 (Kuntz, 2006).

\subsubsection{From humble beginnings: the US experience}

In 1978, Ener-G Foods, a small, two-employee flour packaging company, started production of wheat free, gluten-free bread. The company had previously developed a low-protein bread, with a base of wheat starch, for patients with renal failure awaiting dialysis. Dr Cyrus Rubin, inventor of the Rubin Biopsy Tube and professor of Gastroenterology at the University of Washington and his dietitian, Elaine Hartsook, $\mathrm{PhD}$, requested that the company make gluten-free bread with the restriction that no wheat starch would be used. In the next 30 years, Ener-G Foods would increase their product line to over 150 gluten-free products, pioneering gluten-free foods for people with CD in the United States. Company sales records indicate that during the past 4 years, business has more than doubled (J. Colburn (Ener-G Foods Sales and Marketing Manager), personnel communication, 3 January 2008).

\subsubsection{Gluten-free foods go mainstream}

Consumers have historically looked to natural foods retailers or the Internet for gluten-free food options however, with the demand for gluten-free foods growing, conventional markets currently account for $63 \%$ of gluten-free products purchased. These trends may be due, in part, to increasing availability of gluten-free products. For example, in 2006, the number of gluten-free items increased to over 2400 in natural supermarkets, and to over 1400 in conventional supermarkets (Rourke and Tirone, 2007).

\subsubsection{Growth in the gluten-free market}

Mintel Global New Products Database (GNPD) tracks new product development trends around the world. Mintel Executive Summary on Food Allergies and Intolerance - US April 2007 states that the most common conditions currently impacting the market are CD and lactose intolerance and therefore the products currently seeing the greatest growth on the market are directly relational to the diagnoses of $\mathrm{CD}$ and lactose intolerance. Mintel's market analyst of the 'free-from' (i.e. gluten-free, lactose-free) market has already enjoyed sales growth of over $300 \%$ since 2000 . Sales of products such as wheat-free breads and cakes have grown by almost $120 \%$ over the last 3 years alone, reaching $€ 48$ million ( $\$ 65$ million; see Table 1.2) with the most interest in snack food and bakery items (see Table 1.3). An even

Table 1.2 New products claiming 'gluten free' in the United States by year.

\begin{tabular}{|c|c|}
\hline Year & $\begin{array}{l}\text { Number of new food } \\
\text { and beverage products }\end{array}$ \\
\hline 2004 & 202 \\
\hline 2005 & 332 \\
\hline 2006 & 610 \\
\hline $2007^{*}$ & 636 \\
\hline
\end{tabular}


Table 1.3 Top categories for gluten free in $2007^{a}$.

\begin{tabular}{ll}
\hline Category & $\begin{array}{l}\text { Number of new food } \\
\text { and beverage products }\end{array}$ \\
\hline Snacks & 174 \\
Bakery & 94 \\
Dairy & 62 \\
Confectionery & 56 \\
Sauces and seasonings & 51 \\
Processed fish, meat and egg products & 45 \\
Beverages & 43 \\
Meals and meal centres & 28 \\
Side dishes & 27 \\
Desserts and ice cream & 24 \\
\hline
\end{tabular}

Source: Reprinted with permission of Mintel Global New Products Database (GNPD).

a The year 2007 includes only products tracked from January 2007 to 28 December 2007.

greater increase in new gluten-free product development was seen worldwide (see Tables 1.4 and 1.5) during this time.

\subsubsection{Future needs of gluten-free market development}

Research is underway to find alternative treatments to the GFD. Such advances, although promising, are still in the future. The past decade has brought advances to the medical arena in the ability to diagnose $\mathrm{CD}$, resulting in rapid growth of both the quantity and quality of gluten-free foods. Despite these advances, there is still much to be done to improve the quality of life for people with CD. One major area of concern that must be addressed is the high cost of the GFD. In a survey conducted by The Gluten Intolerance Group, a large celiac support group in the United States, patients indicated that taste and cost were the most important factors when making purchasing decisions for gluten-free products (C. Kupper (RD, CD, Executive Director Gluten Intolerance Group) personnel communication, 10 October 2007). The average cost of a gluten-free food item compared with its gluten-containing counterpart is five times as great (see Table 1.6). Dr Robert Anderson, the chief gastroenterologist for one of Australia's two CD clinics, estimates a GFD costs about $\$ 1000$ per year more than a traditional diet for people with CD living in Australia (Coeliac UK Prescriptions, 2007).

Low-income families experience even greater difficulty in finding comparable glutenfree foods due to their high cost. Currently in the United States and Australia, there is no government subsidy for special dietary foods as in some European countries (e.g. United Kingdom, Italy, Finland) and in New Zealand. People medically diagnosed with CD in the

Table 1.4 New food and beverage products claiming 'gluten free' by year.

\begin{tabular}{lccccccccc}
\hline Year & Argentina & Australia & Brazil & Canada & Egypt & Ireland & Israel & Italy & UK \\
\hline 2004 & 3 & 60 & 56 & 26 & 3 & 21 & 9 & 48 & 118 \\
2005 & 49 & 130 & 49 & 74 & 6 & 19 & 15 & 19 & 334 \\
2006 & 93 & 179 & 307 & 150 & 3 & 30 & 12 & 144 & 180 \\
2007 & 158 & 269 & 418 & 266 & 8 & 41 & 22 & 111 & 421 \\
\hline
\end{tabular}

Source: Reprinted with permission of Mintel Global New Products Database (GNPD). 


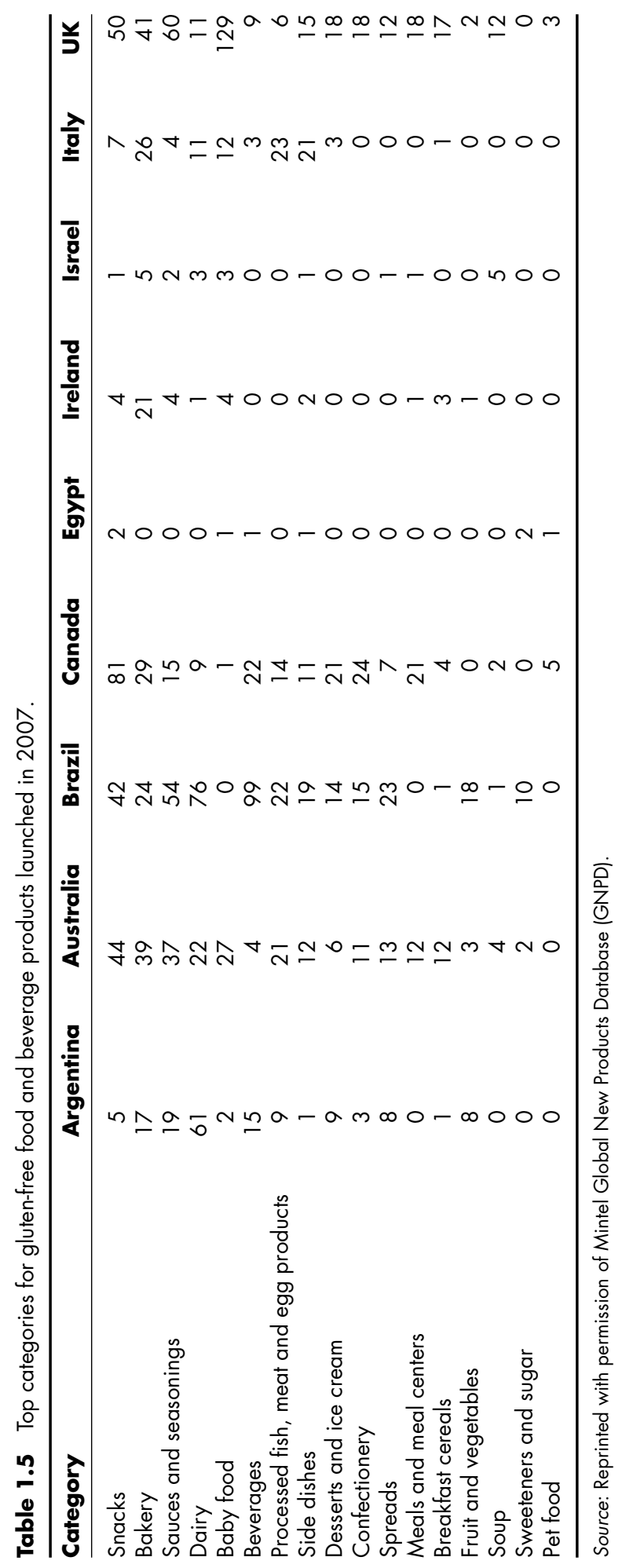


Table 1.6 Cost comparison between wheat product and gluten-free products. ${ }^{a}$

\begin{tabular}{llll}
\hline Wheat flour & $\$ 0.34 / \mathrm{lb}$ & Brown rice flour & $\$ 1.89 / \mathrm{lb}$ \\
Wheat bread & $\$ 1.09 / \mathrm{loaf}$ & Gluten-free bread & $\$ 6.00 / \mathrm{loaf}$ \\
Wheat pasta & $\$ 0.87 / \mathrm{lb}$ & Gluten-free pasta & $\$ 3.69 / \mathrm{lb}$ \\
Chocolate chip cookie & $\$ 2.69 / \mathrm{lb}$ & Gluten-free chocolate chip & $\$ 12.83 / \mathrm{lb}$ \\
Wheat crackers & $\$ 1.63 / \mathrm{lb}$ & Rice crackers & $\$ 9.12 / \mathrm{lb}$ \\
\hline
\end{tabular}

${ }^{a}$ Based on US Department of Labor, Bureau of Labor: consumer price index.

United Kingdom are entitled to receive gluten-free foods on prescription. A survey in 2006 found that over $90 \%$ of people with CD in the United Kingdom obtained their gluten-free food on prescription (Herald Sun, 2008).

The cost of treatment for $\mathrm{CD}$ in developing countries presents a significant challenge to World Health Organization and other relief agencies. It is possible that the prevalence of $\mathrm{CD}$ is increasing in some developing countries as a result of increasing consumption of gluten-containing cereals as provided by such agencies as seen in the Saharawi population (Catassi et al., 1999). These organizations are presented with the challenge that humanitarian interventions should focus on the goal of supplying enough food while being aware of the nutritional outcome to the recipients. Wheat and other gluten-containing grains should be replaced with naturally gluten-free cereals that are present in the developing country. The relief of symptoms people suffer as a result of untreated CD must be available to all who suffer, not only those who can afford the cost of its treatment.

\section{References}

Abu-Zekry, M., Diab, M., Kryszak, D., Catassi, C. and Fasano, A. (2008) Prevalence of Celiac disease in Egyptian children disputes the east-west agriculture-dependent spreading of the disease. Journal of Pediatric Gastroenterology and Nutrition, 47 (2), 136-140.

Agriculture and Agri-Food Canada (2004) United Kingdom: wheat and durum. Bi-weekly Bulletin 17 (9). al-Tawaty, A.I. and Elbargarthy, S.M. (1998) Coeliac disease in north-eastern Libya. Annals of Tropical Paediatrics 18, 27-30.

Ascher, H., Krantz, I. and Kristiansson, B. (1991) Increasing incidence of coeliac disease in Sweden. Archives of Disease in Childhood 66, 608-611.

Ascher, H. and Kristiansson, B. (1994) Childhood coeliac disease in Sweden. Lancet 44, 340-341.

Ben Hariz, M., Kallel-Sellami, M., Kallel, L. et al. (2007) Prevalence of celiac disease in Tunisia: massscreening study in schoolchildren. European Journal of Gastroenterology and Hepatology 19, 687-694.

Berti, I., Horvath, K., Green, P.H.R., Sblattero, D., Not, T. and Fasano, A. (2000) Prevalence of celiac disease among risk groups and the general population in U.S.A. Journal of Investigative Medicine 48 (206), 220A.

Case, S. (2006) Gluten-Free Diet: A Comprehensive Resource Guide. Case Nutrition Consulting, Regina.

Catassi, C., Doloretta Macis, M., Rätsch, I.M., De Virgilis, S. and Cucca, F. (2001) The distribution of DQ genes in the Saharawi population provides only a partial explanation for the high celiac disease prevalence. Tissue Antigens 58, 402-406.

Catassi, C., Fabiani, E., Ratsch, I.M. et al. (1996) The coeliac iceberg in Italy. A multicentre antigliadin antibodies screening for coeliac disease in school-age subsets. Acta Paediatrica Supplement 412, 29-35.

Catassi, C., Kryszak, D., Louis-Jacques, O. et al. (2007) Detection of Celiac disease in primary care: a multicenter case-finding study in North America. The American Journal of Gastroenterology 102, 1454 1460.

Catassi, C., Ratsch, I.M., Fabiani, E. et al. (1984) Coeliac disease in the year 2000: exploring the iceberg. Lancet 343, 200-203. 
Catassi, C., Ratsch, I.M., Fabiani, E. et al. (1995) High prevalence of undiagnosed coeliac disease in 5280 Italian students screened by antigliadin antibodies. Acta Paediatrica 84, 572-576.

Catassi, C., Rätsch, I.M., Gandolfi, L. et al. (1999) Why is celiac disease endemic in the people of Sahara? Lancet 354, 647-648.

Coeliac UK Prescriptions (2007) http://www.coeliac.org.uk/healthcare_professionals/prescriptions/default .asp (accessed 12 October 2008).

Davidson, L.S.P. and Fountain, J.R (1950) Incidence of sprue syndrome with some observation on the natural history. British Medical Journal 1, 1157-1161.

Dossetor, J.F.B., Gibson, A.A.M. and McNeish, A.S. (1981) Childhood coeliac disease is disappearing. Lancet 1, 322-323.

Fasano, A. (1996) Where have all American celiacs gone? Acta Paediatrica Supplement 412, 20-24.

Fasano, A., Berti, I., Gerarduzzi, T., et al. (2003) Prevalence of celiac disease in at-risk and not-at-risk groups in the United States: a large multicenter study. Archives of Internal Medicine 163, 286-292.

Fasano, A. and Catassi, C. (2001) Current approaches to diagnosis and treatment of celiac disease: an evolving spectrum. Gastroenterology 120, 636-651.

Gandolfi, L., Pratesi, R., Cordoba, J.C., Tauil, P.L., Gasparin, M. and Catassi, C. (2000) Prevalence of celiac disease among blood donors in Brazil. The American Journal of Gastroenterology 95, 689-692.

Gee, S.J. (1988) On the coeliac affection. St. Bartholomew's Hospital Report 24, 17-20.

Gluten Intolerance Group (2005) New Food Safety Program-Independent Certification Program for GlutenFree Food Processing. www.foodconsumer.org (accessed 30 January 2008).

Gomez, J.C., Selvaggio, G., Viola, M. et al. (2001) Prevalence of celiac disease in Argentina: screening of an adult population in the La Plata area. The American Journal of Gastroenterology 96, 2700-2704.

Greco, L., Maki, M., DiDonato, F. and Visakorpi, J.K. (1922) Epidemiology of coeliac disease in Europe and the Mediterranean area. In: S. Auricchio and J.K. Visakorpi (eds), Common Food Intolerances 1: Epidemiology of Coeliac Disease, Vol. 2. Dynamic Nutrition Research, Karger, Basel, pp. 25-44.

Grodzinsky, E., Franzen, L., Hed, J. and Strom, M. (1992) High prevalence of celiac disease in healthy adults revealed by antigliadin antibodies. Annals of Allergy 69, 66-70.

Haas, S.V. (1924) The value of the banana in the treatment of coeliac disease. American Journal of Diseases of Children 24, 421-437.

Herald Sun (2007) Gluten-free drives a new mini-industry. http://www.news.com.au/heraldsun/story/ 02198522328396-24331,00.html (accessed 30 January 2008).

Hill, I., Fasano, A., Schwartz, R., Counts, D., Glock, M. and Horvath, K. (2000) Prevalence of celiac disease in at risk groups of children in United States. The Journal of Pediatrics 136, 86-90.

Hill, I.D., Horvath, K. and Fasano, A. (1995) Epidemiology of Celiac disease. The American Journal of Gastroenterology 90, 163-164.

Kaur, G., Sarkar, N., Bhatnagar, S. et al. (2002) Pediatric celiac disease in India is associated with multiple DR3-DQ2 haplotypes. Human Immunology 63, 677-682.

Kolho, K.L., Farkkila, M.A. and Savilahti, E. (1998) Undiagnosed coeliac disease is common in Finnish adults. Scandinavian Journal of Gastroenterology 33, 1280-1283.

Kuntz, L. (2006) Gluten-Free Market Poised for Growth. http://www.foodproductdesign.com/ (accessed 12 July 2006).

Littlewood, J.M., Crollick, A.J. and Richards, I.D.G. (1980) Childhood coeliac disease is disappearing. Lancet 2, 1359.

Logan, R.F.A., Rifking, E.A., Busuttil, A., Gilmous, H.M. and Ferguson, A. (1986) Prevalence and 'incidence' of celiac disease in Edinburgh and the Lothian region of Scotland. Gastroenterology 90, 334-342.

Maki, M., Holm, K., Ascher, H. and Greco, L. (1992). Factors affecting clinical presentation of coeliac disease: role of type and amount of gluten-containing cereals in the diet. In: S. Auricchio and J.K. Visakorpi (eds), Common Food Intolerances 1: Epidemiology of Coeliac Disease, Vol. 2. Dynamic Nutrition Research, Karger, Basel, pp. 76-82.

Maki, M., Kallonen, K., Lahdeaho, M.L. and Visakorpi, J.K. (1988). Changing pattern of childhood coeliac disease in Finland. Acta Paediatrica Scandinavica 77, 408-412.

Mazzetti di Pietralata, M., Giorgetti, G.M., Gregori, M. et al. (1992) Sub-clinical coeliac disease. The Italian Journal of Gastroenterology 24, 352-354.

Mediene, S., Hakem, S., Bard, J.M. et al. (1995) Serum lipoprotein profile in Algerians patients with celiac disease. Clinica Chimica Acta 31, 189-196.

Meeuwisse, G.W. (1970) Diagnostic criteria in coeliac disease. Acta Paediatrica Scandinavica 59, 461-463. 
Mylotte, M., Egan-Mitchell, B., McCarthy, C.F. and McNicholl, B. (1973) Incidence of coeliac disease in the west of Ireland. British Medical Journal I, 703-1705.

NIH Consensus Statement on Celiac Disease (2004) NIH Consensus and State-of-the-Science Statements $21(1), 3-4,16$.

Not, T., Horvath, K., Hill, I.D. et al. (1998) Celiac disease risk in the USA: high prevalence of antiendomysium antibodies in healthy blood donors. Scandinavian Journal of Gastroenterology 33, 494-498.

Rawashdeh, M.O., Khalil, B. and Raweily, E. (1996) Celiac disease in Arabs. Journal of Pediatric Gastroenterology and Nutrition 23, 415-418.

Rossi, T.M., Slbini, C.H. and Kumar, V. (1993) Incidence of celiac disease identified by the presence of serum endomysial antibodies in children with chronic diarrhea, short stature, or insulin-dependent diabetes mellitus. Journal of Pediatrics 123, 262-264.

Rourke, K. and Tirone, A. (2007) Celiac Disease: Continuing Awareness and Market Growth. www.naturalproductsinsider.com (accessed 4 June 2007).

Shahbazkhani, B., Forootan, M., Merat, S. et al. (2003) Coeliac disease presenting with symptoms of irritable bowel syndrome. Alimentary Pharmacology and Therapeutics 18, 231-235.

Sood, A., Midha, V., Sood, N., Avasthi, G. and Sehgal, A. (2006) Prevalence of celiac disease among school children in Punjab, North India. Journal of Gastroenterology and Hepatology 21, 1622-1625.

Stevens, F.M., Egar-Mitchell, B., Cryan, E., McCarthy, C.F. and McNicholl, B. (1987) Decreasing incidence of coeliac disease. Archives of Disease in Childhood 62, 465-468.

Talley, N.J., Valdovinos, M., Petterson, T.M., Carpenter, H.A. and Melton, L., Jr. (1994) Epidemiology of celiac sprue: a community-based study. American Journal of Gastroenterology 89, 843-846.

Van Stirum, J., Baerlocher, K., Fanconi, A., Gugler, E. and Shmerling, D.H. (1982) The incidence of coeliac disease in children in Switzerland. Helvetica Paediatrica Acta 37, 421-430.

Weile, B. and Krasilnifoff, P.A. (1993) Extremely low incidence rate of celiac disease in the Danish population of children. Journal of Clinical Epidemiology 46, 661-664.

Yachha, S.K. (2006) Celiac disease: India on the global map. Journal of Gastroenterology and Hepatology 21, 1511-1513.

van Berge-Henegouwen, G. and Mulder, C. (1993) Pioneer in the gluten free diet: Willem-Karel Dicke 1905-1962, over 50 years of gluten free diet. Gut 34 (11), 1473-1475.

Department of Health and Human Services Food and Drug Administration (2007) Food Labeling; GlutenFree Labeling of Foods. http://www.fda.gov/OHRMS/DOCKETS/98fr/05n-0279-npr0001.pdf (accessed 30 January 2008).

Codex Alimentarius Commission (2007) http://www.fda.gov/OHRMS/DOCKETS/98fr/05n-0279-npr0001 .pdf (accessed 30 January 2008). 